\section{Replacement of animals in research will never be possible}

SIR - Your Editorial 'Call to action' (Nature 456, 281-282; 2008), concerning the draft of the new European directive on the use of animals in scientific research, correctly points out the risk of severely limiting the use of non-human primates in invasive studies of brain function. Performing such experiments requires humane treatment of animals and painless experimental procedures. This 'refinement' of procedure is the first of the 3Rs, the philosophy underlying the European Union (EU) directive. During the past 20 years, technical improvements have significantly reduced both the time and the number of animals used in a project, while increasing the data yield. Thus, the second of the 3Rs, 'reduction', is already firmly established.

What needs to be clearly appreciated is that 'replacement' (the third R) of this type of research will never be possible. The current draft of the EU directive, in confining the use of non-human primates as far as possible to projects aimed at understanding life-threatening diseases, takes a direction that is both incorrect and illusory, towards a future ban that it considers desirable. As stated in your Editorial, this is a real threat. We must combat it with strength and without compromise. A ban could be justified only if and when all brain function is understood, and if no further challenge is posed to neuroscience by the evolution of modern societies and their pathologies. Obviously, neither of these conditions will ever be realized.

From my privileged observatory as chair of the Programme of European Neuroscience Schools (http://fens.mdc-berlin.de/pens), I can testify to the increasing interest among the younger generation in the integrative study of brain function. At the same time, I stress the dramatic negative consequences that a severe limitation or ban on the use of non-human primates will have on education, in a discipline that currently places Europe at the forefront of modern research in neuroscience.

Behavioural studies have the power to shed light on some of the most common neurological syndromes that affect our societies. They have already provided encouraging first answers about Parkinson's disease and the principles underlying neural prosthetics and brain-machine interface devices, among other examples. The enforced abandonment of research on great apes has phased out experimental studies on, for example, brain evolution, malaria, hepatitis $C$ and respiratory syncytial virus infection. Prohibiting studies on primates will confine Europe to the periphery of the neuroscience and biomedical arena, with negative consequences for the quality of life of future generations.

Roberto Caminiti Department of Physiology and Pharmacology, Sapienza University of Rome, Piazzale Aldo Moro 5, 00185 Rome, Italy

\section{Western prosperity is based on resources that are running out}

\section{SIR - In response to the lack of a flagship achievement by economics, as noted by Jean-Philippe Bouchaud in his Essay 'Economics needs a \\ 'Subspecies' and 'race' should not be used as synonyms} scientific revolution' (Nature 455, 1181; 2008), Jesper Stage proposes in Correspondence that the prosperity of western societies is one such achievement ('Speaking up for economicsciences modelling' Nature 456, 570; 2008). However, this prosperity is mainly based on the use of non-renewable resources and therefore is probably spurious.

Several hundred million years were needed to form the fossil energy that will be exhausted during a few hundred years. This is roughly equivalent to spending all one's annual income during the first 30 seconds of a year. In particular, the frenzy to automate processes in order to increase competitiveness leads to rapid exhaustion of available resources, for example through over-fishing or degradation of soils.

All current growth-based economic models imply massive use of non-renewable resources and environmental degradation. These models are not sustainable, even in the short term.

As early as 160 years ago, John Stuart Mill affirmed that "the richest and most prosperous countries would very soon attain the stationary state" (Principles of Political Economy Longmans, 1848). In contrast to that time, when resources were being used up at a rate that was several orders of magnitude slower than today, a phase of economic degrowth is necessary before a stationary state can be reached. It would be a major achievement of economics to achieve such a degrowth without social and political disasters.

Hervé Philippe Département de Biochimie, Université de Montréal, 2900 Edouard Montpetit, H3C 3J7 Montréal, Québec, Canada e-mail: herve.philippe@umontreal.ca

SIR - Your News Feature 'Disputed definition' looks at the pitfalls of discussing race with regard to humans (Nature 455, 1025-1026; 2008). Social norms now effectively prohibit, with good cause, the assumption that there are biological distinctions among human races. Thankfully, too, the heyday of eugenics has long since passed.

You do not mention, however, that the term 'race' is often treated as a synonym for the taxonomic rank of subspecies (for example, see E. Mayr Principles of Systematic Zoology 44, McGraw-Hill, 1969). An unwitting reader might infer that the term 'subspecies' is equally problematic and should therefore be equally eschewed. Some, indeed, would argue as much (for example, E. O. Wilson and W. L. Brown Syst. Zool. 2, 97-111; 1953; and R. M. Zink Proc. R. Soc. B 271, 561-564; 2004).

However, 'subspecies' remains a useful taxonomic division that enriches our understanding of evolution and biogeography. It provides a handle for identifiable units of geographic variation and, therefore, frequently acts as impetus for investigations into the evolution of particular species.

Subspecies can be defined as "a collection of populations occupying a distinct breeding range and diagnosably distinct from other such populations" (M. A. Patten and P. Unitt Auk 119, 26-35; 2002), representing a level of biological organization below that of species. This definition is not arbitrary, as there are clear ways of describing a subspecies objectively.

Given the problems associated with the term 'race', conflating 'race' and 'subspecies' is potentially misleading and unnecessarily undermines the proper definition of subspecies. So stop the common practice of using 'race' as a synonym for 'subspecies' (as, for example, in Field Guide to the Birds of North America National Geographic, 5th edn, 2006). Let us relegate that murky term for use by sociologists and politicians enamoured of purported differences among humans.

Michael A. Patten Oklahoma Biological Survey, University of Oklahoma, Norman, Oklahoma 73019, USA e-mail:mpatten@ou.edu

Contributions may be submitted to correspondence@nature.com; please see the Guide to Authors at http://tinyurl.com/373jsv. Comments and debate are also welcomed at http://blogs.nature. com/nautilus. 